\title{
Accommodating dissent
}

\section{Providing cures for health problems isn't enough, if people's personal or cultural beliefs clash with the scientific approach. Policy-makers must recognize and engage with these objections.}

\begin{abstract}
Melissa Leach
Dismissing public and political concerns about health interventions as unscientific, irrational or misled fails to do justice to the different perspectives in play. It widens gulfs between those promoting the technologies and those who could benefit from them. It is why we see backlashes to even the best-intentioned initiatives. These backlashes signal the need for new forms of dialogue to enable scientists, policymakers and citizens to navigate the multilayered politics emerging around science and technology.
\end{abstract}

For example, in the Gambia, programmes of antiretroviral treatments for HIV and AIDS have been disrupted since January 2007 when its president, Yahya Jammeh, announced a "cure" for AIDS based on Koranic incantations and herbs. As people living with HIV have come forward to join the president's programme amid heavy state publicity and security, biomedical critics have found it difficult to be heard, and to dispute the controversial laboratory blood tests that Jammeh claims prove the efficacy of his cure.

In Nigeria, the Global Polio Eradication Initiative was derailed in 2003 when three northern states rejected the oral polio vaccine. Datti Ahmed, a doctor and president of Nigeria's Supreme Council for Sharia Law, told journalists: "We believe that modern-day Hitlers have deliberately adulterated the oral polio vaccine with antifertility drugs and contaminated it with certain viruses which are known to cause HIV and AIDS." Although vaccination was allowed to resume in 2004, worry in northern communities still besets the campaign. Polio is now on the rise in the area, and is spreading across Africa.

Such anxieties about and rejection of science, its technologies and safety, are not exotic phenomena. In Britain, parental concern about the measles, mumps and rubella (MMR) vaccination has led to an alarming rise in the rate of measles among incompletely vaccinated populations since the late 1990s.

Scientists, policy-makers and professionals often respond to such controversies by urging that 'sound science' must rise above politics. This unwittingly casts campaigners and the public as ignorant, irrational, mistrustful or simply misled by the media. Yet such images are themselves simplistic and misleading. They overlook the positive reasons why people question or seek alternatives to science, grounded in their own knowledge and experience. Equally misleading are policy stereotypes proposing that trust and rationality are breaking down in Europe, whereas in Africa they are not yet achieved. In both cases, health policy and professional organizations say that the solution is simply better communication of the science and risks involved.

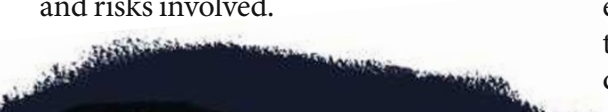

(n) preted as having other effects, such as on fertility.

The campaign's mass of resources and political attention failed to boost the locally valued primary health-care systems that were in a state of near collapse. Local authorities and people alike interpreted the campaign in wider political terms, as examples of international, central and southern Nigerian political interests seeking to undermine further the strength of the northern states.

A more balanced appreciation of such diverse perspectives is vital. It could be assisted by effective collaboration among social scientists, natural scientists and decision-makers in designing and planning health programmes, as well as responding to controversies. International agencies and national health services could promote and facilitate this. New forums facilitated by independent bodies - such as non-governmental organizations - will also be needed to bring such agencies together in deliberation with scientists, local authorities and citizens' groups. This will help ensure that investments in science and technology - whether for downstream applications or for research and innovations - are firmly enmeshed with inclusive debate about the social and political values they serve.

Melissa Leach is director of the ESRC STEPS Centre, Institute of Development Studies, University of Sussex, Brighton, East Sussex BN1 9RE, UK.

For more essays and information see http://nature.com/ nature/focus/scipol/index.html. 